\title{
Multiattribute Response of Maize Genotypes Tested in Different Coastal Regions of Brazil
}

\author{
Lúcio Borges de Araújo, ${ }^{1}$ Mario Varela Nualles, ${ }^{2}$ Mirian Fernandes Carvalho Araújo, ${ }^{1}$ \\ and Carlos Tadeu dos Santos Dias ${ }^{3}$ \\ ${ }^{1}$ Faculty of Mathematics, Federal University of Uberlândia, Avenida João Naves de Ávila, 2.121, 38400-902 Uberlândia, MG, Brazil \\ ${ }^{2}$ Department of Mathematics, Instituto Nacional de Ciencias Agrícolas (INCA), km 3.5, San José de Las Lajas, 3700 Habana, Cuba \\ ${ }^{3}$ Department of Exact Sciences, University of São Paulo, Avenida Pádua Dias, 11, 13418-900 Piracicaba, SP, Brazil
}

Correspondence should be addressed to Lúcio Borges de Araújo, lucio@famat.ufu.br

Received 21 March 2011; Revised 8 June 2011; Accepted 13 September 2011

Academic Editor: Ravindra N. Chibbar

Copyright () 2011 Lúcio Borges de Araújo et al. This is an open access article distributed under the Creative Commons Attribution License, which permits unrestricted use, distribution, and reproduction in any medium, provided the original work is properly cited.

This work applies the three mode principal components analysis to analyze simultaneously the multiple attributes; to fit of models with additive main effects and multiplicative interaction effects (AMMI models) and the regressions models on sites (SREG models); to evaluate, respectively, the multivariate response of the genotype $\times$ environment interaction and the mean response of 36 genotypes of corn tested in 4 locations in Brazil. The results were presented by joint plots to identify the best genotypes for their adaptability and performance in the set of attributes.

\section{Introduction}

The multienvironment trials are conducted to estimate the genetic stability, to evaluate the performance of the genotypes in different environmental conditions, and to quantify and interpret the genotype $\times$ environment interaction (GEI), in such a way to select the best genotypes that will be recombined and planted in other years and other environments in the next selection cycle. Some statistical models are used to evaluate the behavior of the genotypes; the most recently proposed methods are based on the singular value decomposition of the GEI matrix.

In [1], the two-way interaction using the principal components analysis (PCA) are explained and considered in their model only one multiplicative term. An extension of these models was made in [2], which applies the PCA to decompose the two-way interaction in several multiplicative terms. This model was called as additive main effects and multiplicative interaction effects model (AMMI) by Gauch [3].
Another class of the Linear-bilinear model used in multienvironment trials is the sites regression model (SREG) described by [4]. In this case, the main objective is to evaluate the response of the genotype in each environment. The basic difference in relation to AMMI models is that the effect of genotype is introduced into the residual interaction. This model was used in [5] for clustering of environmental data with no cross-interaction.

Gabriel [6] describes the least-square adjustment of the AMMI model, first estimating the additive effects of the model and then making the decomposition in singular values of the matrix $(Z)$ of interaction residuals. The results can be interpreted by graphics called biplot [7] that reflects in reduced dimensions the most important aspects of the GEI, in the case the AMMI model, or the performance of genotypes in different environments, for the case of the model SREG.

The researchers in the multienvironmental trials evaluate multiple attributes and must select the best genotypes taking in to account its adaptability and performance in the set of 
attributes. With the AMMI and SREG models, it is possible to study the genotypes in a single attribute. However, if we want a response with multiple attributes, it is necessary to apply a statistical technique that allows working with threedimensional structure data.

In [8], a three mode principal components analysis (PCA3) is proposed, in order to find the least-square estimates in the model of Tucker [9]. This procedure was used to study the GEI with multiples attributes [10-13]. The method also was applied by $[14,15]$ to study the threeway interaction in agricultural experiments where genotypes are tested in different locations over several years.

In this work, we used the three mode principal component analysis to explain, in reduced dimensions, the most important aspects of multiattribute performance of the 36 genotypes of maize tested in 4 regions of Brazil. First, we studied the GEI using the AMMI model with multiple attributes as described in $[15,16]$ and finally studied the genotypes in relation to the mean environment for multiple attributes as described in [17].

\section{Materials and Methods}

Data are from experiments with 36 genotypes of maize (first mode, $i=1, \ldots, 36)$, evaluated in 4 locations of Brazil $\left(S_{1}\right.$ : Rio Branco-AC, $S_{2}$ : Milagres-CE, $S_{3}$ : Linhares-ES, cohesive soil Oxisol, $S_{4}$ : Linhares-ES, soil-LVA-Distrophic LVD11; second mode, $j=1, \ldots, 4)$. In each of the experiments, 10 attributes were evaluated: $X_{1}$ : flowering (days), $X_{2}$ : plant height $(\mathrm{cm}), X_{3}$ : corn-cob length $(\mathrm{cm}), X_{4}$ : percentage of plants laid, $X_{5}$ : percentage of plants broken, $X_{6}$ : final stand, $X_{7}$ : number of spikes, $X_{8}$ : percentage of patients corn-cobs, $X_{9}$ : weight of spikes $(\mathrm{kg} / \mathrm{ha})$, and $X_{10}$ : weight of grains (kg/ha) (third mode, $k=1, \ldots, 10)$.

The data were obtained using a simple lattice design in duplicate $6 \times 6$ with 4 replications. Each plot consisted of two rows of $5 \mathrm{~m}$, used entirely. The spacing between rows was $1 \mathrm{~m}$ and between hills it was $0.40 \mathrm{~m}$. Each plot consisted of 26 hills and each hole with 3 seeds. The seeds used in the tests were sent by the National Center for Research in Maize and Sorghum-CNPMS of Empresa Brasileira de Pesquisa Agropecuária-EMBRAPA, already counted, and contained in envelopes coded with the number of genotype and number of the parcel.

2.1. Statistical Processing. Each attribute $k(k=1, \ldots, 10)$ was calculated according to model the estimates corresponding to interactions: $\left(y_{i j k .}-y_{i . k .}-y_{. j k}+y_{. . k}\right)$ for AMMI model or $\left(y_{i j k .}-y_{. j k}\right)$ for SREG model, where $y_{i j k \text {. }}$ represents the mean corresponding to attribute $k$ for the genotype $i$ in location $j ; y_{i . k}$. represents the mean corresponding to the attribute $k$ for the genotype $i ; y . j k$. represents the mean corresponding to the attribute $k$ in location $j ; y_{\text {... }}$. represents the overall mean of the data for the attribute $k$. Two tridimensional arrays $(\underline{\mathbf{Z}})$ were constructed with the values obtained using the AMMI model or the SREG model, that is, for each model, the value $z_{i j k}$ in the array $\underline{\mathbf{Z}}$ represents the residue to the genotype $j$ in the location $j$, for the attribute $k$. Each array was applied to three mode principal components analysis. Therefore, this methodology can be used for any dataset.

2.2. Three Mode Principal Component Analysis. The method consists of finding the least-square estimators for the Tucker model:

$$
z_{i j k .}=\sum_{p=1}^{P} \sum_{q=1}^{Q} \sum_{r=1}^{R} a_{i p} b_{j q} c_{k r} g_{p q r}
$$

where $a_{i p}, b_{j q}$, and $c_{k r}$ are the elements of the principal components matrix (A, B, and $\mathbf{C}$ ) associated with each respective mode, and in this example, $\mathbf{A}$ is the principal components matrix for the genotype mode, $\mathbf{B}$ is the principal component matrix for the location mode, and $\mathbf{C}$ is the principal component matrix for the attribute. $\mathbf{G}$ is a core array of the three way, where the element $g_{p q r}$ represents the relationship between the $p$ th component of the first mode with the $q$ th component of the second mode and with the $r$ th component of the third mode. $P$ is the rank of the matrix $Z_{1 ; 2 \subset 3}$ that contains the residuals of the interaction with all the variables, calculated as an AMMI model or as an SREG model. In this matrix, the rows represent the levels of the genotypes and the columns represent combinations of the levels of locations and attributes. Similarly, $Q$ and $R$ are defined as the rank of matrices $Z_{2 ; 1 \subset 3}$ and $Z_{3 ; 1 \subset 2}$.

To select the number of principal components retained for each mode, the algorithm proposed by [18] was used, based on successive eliminations until finding the optimal solution.

\subsection{Biplot Representation for Three Marker Matrices. A biplot} is a simultaneous representation of rows and columns of a matrix (two-way array) in terms of directions and projections [7]. When we have several matrices, or when we are working with data contained in a three-way array, it is necessary to project on the principal components of one of the modes. Suppose we are going to project onto the components of the second mode (locations) and $Q_{1}$ represents the number of principal components retained in this mode; then we have to obtain the matrices $\mathbf{A} \times \mathbf{G}_{q} \times$ $\mathbf{B}^{\prime}, q=1, \ldots, Q_{1}$, and require one biplot for each matrix. $\mathbf{G}_{q}$ is the part of $\underline{\mathbf{G}}$ associated with the component $q$ of the second mode. This procedure is described in [8] and commonly called a joint plot.

\section{Results and Discusions}

3.1. AMMI Multiattribute. Table 1 shows the results of the 6 $\times 2 \times 3$ solution obtained by applying the three mode principal component analysis to the three-way array with the residuals of interaction obtained for the AMMI model with 10 attributes simultaneously. This solution explained $44.92 \%$ of the total variability, therefore, this percentage is significant in relation to ten attributes measured in the research. The components associated with the genotype mode explain, respectively, $12.85 \%, 11.70 \%, 6.37 \%, 6.22 \%$, 


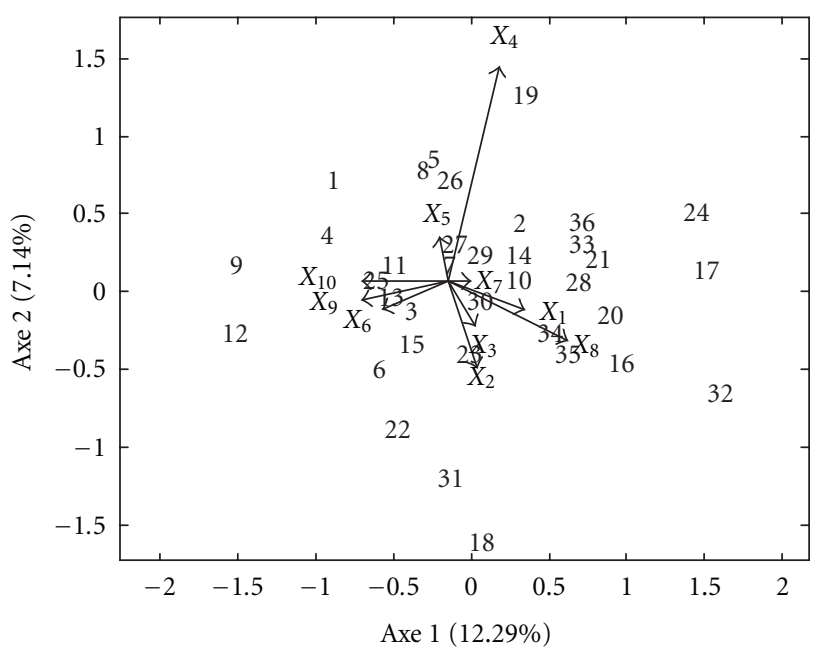

Figure 1: Joint plot conditioned on the first component the location mode for AMMI model.

$4.93 \%$, and $2.84 \%$, the components of the location mode explain, respectively, $25.49 \%$ and $19,44 \%$, and the components of the attribute mode explain, respectively, $22.6 \%$, $11.6 \%$, and $11.0 \%$ of the total variability.

Component 1 of the local mode is characterized by all the sites with relatively high weights (Matrix B, Table 1). This component is described by contrast between sites $S_{1}$ and $S_{2}$ (Rio Branco-AC and Milages-CE) versus sites $S_{3}$ and $S_{4}$ (Linhares-ES oxisol cohesive soil and Linhares-ES LVAdystrophic-LVD11 soil).

Figure 1 shows the most important genotypes $\times$ locations interactions for the different attributes evaluated, mainly for the attribute $X_{4}$ (percentage of plants laid). Genotype 19 interacts positively in locations $S_{1}$ and $S_{2}$ and negatively in locations $S_{3}$ and $S_{4}$ for attribute $X_{4}$. Genotypes 18 and 31 have a behavior completely contrary to genotype 19 , that is, they interact positively in the locations $S_{3}$ and $S_{4}$ and interact negatively in locations $S_{1}$ and $S_{2}$ for the attribute $X_{4}$. In regard to variable $X_{2}$ (plant height), the behavior of these genotypes is totally contrary to variable $X_{4}$, for example, the genotype 19 interacts negatively in locations $S_{1}$ and $S_{2}$ and positively in the locations $S_{3}$ and $S_{4}$ for the attribute $X_{2}$.

Figure 1 also shows the contrast between the genotypes 9 and 12 of the genotypes 17, 24, and 32. The first group interacts positively in the attributes $X_{6}, X_{9}$, and $X_{10}$ for locations $S_{1}$ and $S_{2}$ and negatively in these attributes for the locations $S_{3}$ and $S_{4}$. Genotypes 17, 24, and 32 have positive interaction in the attributes $X_{1}$ and $X_{8}$ in the locations $S_{1}$ and $S_{2}$ but have negative interactions in locations $S_{3}$ and $S_{4}$ in these attributes.

Figure 2 shows the projection biplot onto the second component of locations, which is dominated by contrast of the sites $S_{1}$ and $S_{2}$ with respective weights $(-0.75$ and 0.64) (Matrix B, Table 1). In this graphic, it is possible to study the genotypes $\times$ locations interaction in different attributes for the locations $S_{1}$ and $S_{2}$. For example, genotype 15 interacts positively in the local $S_{1}$ for attribute $X_{7}$ and interacts negatively in local $S_{2}$ for this attribute. There is also
TABLE 1: $6 \times 2 \times 3$ solution for AMMI model with multiples attributes.

(a) Matrix A

\begin{tabular}{|c|c|c|c|c|c|c|}
\hline & $p_{1}$ & $p_{2}$ & $p_{3}$ & $p_{4}$ & $p_{5}$ & $p_{6}$ \\
\hline$G_{1}$ & 0.16 & -0.1 & -0.2 & 0.3 & 0.01 & 0.29 \\
\hline$G_{2}$ & 0.03 & 0.12 & 0.08 & 0.02 & -0.1 & 0.16 \\
\hline$G_{3}$ & 0.12 & -0 & -0.2 & -0 & -0 & -0.2 \\
\hline$G_{4}$ & 0.1 & -0.2 & 0.33 & 0.05 & -0.3 & -0.2 \\
\hline$G_{5}$ & 0.26 & 0.19 & -0.2 & 0.12 & -0 & 0.12 \\
\hline$G_{6}$ & -0.1 & -0.3 & -0.1 & 0.06 & -0.1 & -0 \\
\hline$G_{7}$ & 0 & -0.1 & -0.3 & 0.23 & 0.03 & 0.08 \\
\hline$G_{8}$ & 0.08 & 0.02 & 0.2 & 0.17 & -0 & 0.05 \\
\hline$G_{9}$ & 0.16 & -0.3 & 0.08 & 0.1 & -0.2 & 0.21 \\
\hline$G_{10}$ & -0 & 0.02 & 0.08 & -0 & 0.06 & 0.09 \\
\hline$G_{11}$ & 0.15 & -0 & 0.19 & -0.1 & 0.22 & 0.22 \\
\hline$G_{12}$ & 0.25 & -0.3 & 0.04 & -0.1 & 0.01 & -0.1 \\
\hline$G_{13}$ & 0.08 & -0.1 & 0.06 & -0.1 & -0.2 & -0 \\
\hline$G_{14}$ & 0.19 & 0.28 & 0.16 & -0.2 & 0.12 & 0.07 \\
\hline$G_{15}$ & -0.2 & -0.3 & 0.34 & 0.13 & 0.58 & -0.1 \\
\hline$G_{16}$ & -0.3 & 0 & 0.11 & -0.1 & -0.1 & 0.09 \\
\hline$G_{17}$ & -0.2 & 0.22 & 0.11 & -0 & 0.02 & 0.09 \\
\hline$G_{18}$ & -0.1 & -0.2 & -0.1 & -0.5 & -0.2 & -0 \\
\hline$G_{19}$ & 0.02 & 0.16 & 0.33 & 0.25 & -0.3 & -0.4 \\
\hline$G_{20}$ & -0.2 & 0.08 & 0.08 & -0.1 & -0.1 & 0.02 \\
\hline$G_{21}$ & -0.1 & 0.14 & -0 & 0.02 & 0 & 0.15 \\
\hline$G_{22}$ & 0.08 & -0.1 & 0.03 & -0.3 & 0.03 & -0.1 \\
\hline$G_{23}$ & 0.11 & 0.06 & 0 & -0.3 & -0.1 & 0.19 \\
\hline$G_{24}$ & -0.3 & 0.11 & 0.02 & 0.15 & -0.2 & -0 \\
\hline$G_{25}$ & 0.01 & -0.2 & -0.2 & 0.17 & 0.03 & 0.21 \\
\hline$G_{26}$ & 0.18 & 0.13 & 0.02 & -0 & 0.28 & -0.1 \\
\hline$G_{27}$ & 0.1 & 0.06 & -0.1 & 0.12 & 0.02 & 0.07 \\
\hline$G_{28}$ & -0 & 0.21 & -0.1 & 0 & 0.15 & -0.3 \\
\hline$G_{29}$ & 0.03 & 0.03 & -0 & 0.07 & 0.05 & -0.3 \\
\hline$G_{30}$ & 0.09 & 0.1 & -0.1 & -0 & 0.01 & 0.09 \\
\hline$G_{31}$ & 0.02 & -0.1 & -0.3 & -0.3 & 0.05 & -0.4 \\
\hline$G_{32}$ & -0.5 & -0 & -0.2 & 0.1 & 0.09 & -0.1 \\
\hline$G_{33}$ & -0 & 0.18 & 0.06 & 0.04 & 0.04 & -0.1 \\
\hline$G_{34}$ & 0 & 0.13 & 0 & -0.1 & 0.22 & -0.2 \\
\hline$G_{35}$ & -0.2 & -0.1 & -0.1 & 0 & -0.1 & -0.1 \\
\hline$G_{36}$ & -0 & 0.15 & -0.1 & 0.08 & -0.1 & -0.2 \\
\hline
\end{tabular}

(b) Matrix B

\begin{tabular}{lcc}
\hline & $q_{1}$ & $q_{2}$ \\
\hline$S_{1}$ & 0.42 & -0.8 \\
$S_{2}$ & 0.56 & 0.64 \\
$S_{3}$ & -0.4 & 0.11 \\
$S_{4}$ & -0.6 & 0 \\
\hline
\end{tabular}

(c) Matrix $\mathbf{C}$

\begin{tabular}{cccc}
\hline & $r_{1}$ & $r_{2}$ & $r_{3}$ \\
\hline$X_{1}$ & 0.12 & -0.1 & 0.23 \\
$X_{2}$ & -0.1 & 0.06 & 0.19 \\
\hline
\end{tabular}


(c) Continued.

\begin{tabular}{lccc}
\hline & $r_{1}$ & $r_{2}$ & $r_{3}$ \\
\hline$X_{3}$ & -0.1 & -0 & 0.12 \\
$X_{4}$ & 0.25 & -0.6 & -0.6 \\
$X_{5}$ & 0.01 & 0.24 & -0.5 \\
$X_{6}$ & -0.5 & -0 & -0 \\
$X_{7}$ & -0.3 & -0.7 & 0.39 \\
$X_{8}$ & 0.24 & 0.07 & 0.27 \\
$X_{9}$ & -0.5 & 0.04 & -0.2 \\
$X_{10}$ & -0.5 & 0.01 & -0.2 \\
\hline
\end{tabular}

(d) Array $\underline{\mathbf{G}}$

\begin{tabular}{ccccccc}
\hline & $q_{1} r_{1}$ & $q_{1} r_{2}$ & $q_{1} r_{3}$ & $q_{2} r_{1}$ & $q_{2} r_{2}$ & $q_{2} r_{3}$ \\
\hline$P_{1}$ & -5.4 & -0.9 & -4.1 & -5.3 & -0.7 & 1.48 \\
$P_{2}$ & 6.06 & -2 & -0.2 & -5.4 & -0.3 & 0.63 \\
$P_{3}$ & -1 & -5.5 & 0.92 & 0.87 & -1.7 & -1.7 \\
$P_{4}$ & 1.43 & -0.9 & -5.1 & 1.91 & 1.76 & -1.5 \\
$P_{5}$ & -0.8 & -1.1 & 1.5 & -0.9 & 4.93 & -0.5 \\
$P_{6}$ & 0.2 & -1.2 & -0.2 & 1.12 & 0.47 & 3.74 \\
\hline
\end{tabular}

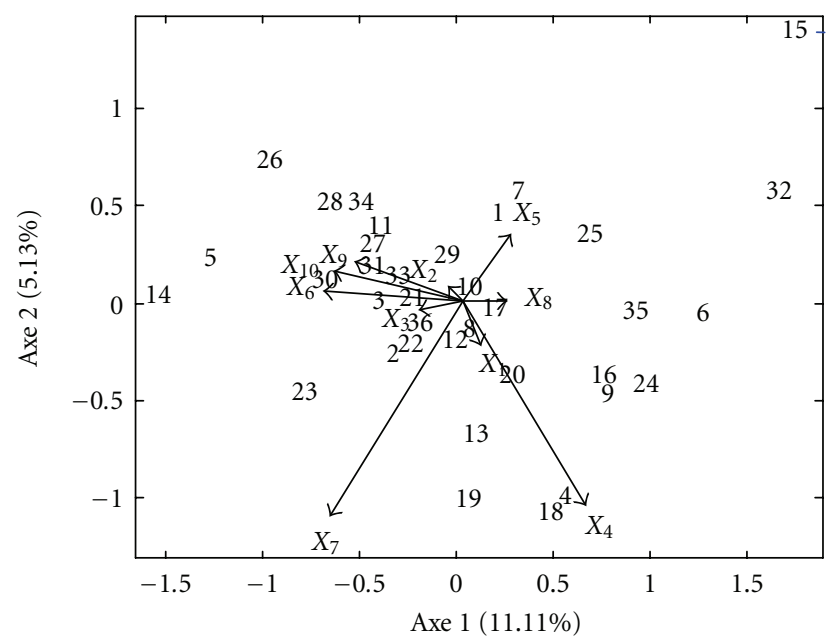

FIgURE 2: Joint plot conditioned on the second component the location mode for AMMI model.

the contrast of genotypes 4 and 18 in relation to genotype 26 . The genotype 26 interacts positively with the attribute $X_{4}$ in local $S_{1}$ and interacts negatively in local $S_{2}$ for this attribute, then in $S_{2}$ there are a few percentage of plant laid, and in $S_{1}$ many percentage of plant laid. The contrast between the genotypes 5 and 14 in relation to the genotypes 6 and 35 for attributes $X_{6}, X_{9}$, and $X_{10}$ can be observed. The first group had positive interactions with $S_{2}$ and negative with $S_{1}$ and showed that in the $S_{2}$ there are high values of final stand, weight of spikes, and weights of grains.

3.2. SREG Multiattribute. Table 2 shows the results of the $5 \times$ $2 \times 3$ solution obtained by applying the three mode principal components analysis to the three-way array containing the residuals of interaction for the SREG model with 10 attributes simultaneously. This solution explained $53.70 \%$
TABle 2: $5 \times 2 \times 3$ solution for SREG model with multiples attributes.

(a) Matrix $\mathbf{A}$

\begin{tabular}{|c|c|c|c|c|c|}
\hline & $p_{1}$ & $p_{2}$ & $p_{3}$ & $p_{4}$ & $p_{5}$ \\
\hline$G_{1}$ & 0.07 & -0 & 0.28 & -0.4 & 0 \\
\hline$G_{2}$ & 0 & -0.2 & -0.1 & 0.12 & -0.1 \\
\hline$G_{3}$ & 0.14 & 0.11 & -0.1 & -0.1 & 0.07 \\
\hline$G_{4}$ & -0.1 & -0.5 & 0.02 & -0.1 & 0.03 \\
\hline$G_{5}$ & 0.01 & -0.1 & -0 & -0.1 & 0.1 \\
\hline$G_{6}$ & 0.02 & -0.1 & 0.1 & -0 & 0.01 \\
\hline$G_{7}$ & -0.1 & -0.2 & 0.15 & -0.1 & 0.28 \\
\hline$G_{8}$ & 0.09 & 0.25 & -0.2 & -0.1 & 0.11 \\
\hline$G_{9}$ & 0.06 & 0.13 & -0.2 & -0.3 & 0.06 \\
\hline$G_{10}$ & 0.3 & -0 & 0.02 & 0.2 & -0 \\
\hline$G_{11}$ & 0.23 & 0.08 & 0 & -0.1 & -0.2 \\
\hline$G_{12}$ & 0.07 & -0 & -0.2 & -0.3 & 0.05 \\
\hline$G_{13}$ & -0.3 & 0.04 & -0.1 & -0.2 & 0.03 \\
\hline$G_{14}$ & -0.1 & 0.18 & -0.3 & -0.1 & -0.1 \\
\hline$G_{15}$ & -0.3 & 0.05 & -0.3 & 0.03 & -0.1 \\
\hline$G_{16}$ & -0.3 & 0.25 & -0 & 0.07 & -0.1 \\
\hline$G_{17}$ & -0.2 & 0.16 & 0.17 & 0.13 & -0.1 \\
\hline$G_{18}$ & 0.11 & 0.03 & 0.18 & -0 & -0.3 \\
\hline$G_{19}$ & -0 & 0.16 & 0.14 & -0.2 & 0.22 \\
\hline$G_{20}$ & -0.1 & -0.2 & 0.07 & 0.27 & -0.2 \\
\hline$G_{21}$ & -0.2 & -0 & 0.07 & 0.03 & 0.15 \\
\hline$G_{22}$ & -0.1 & -0.2 & -0.1 & -0 & -0.5 \\
\hline$G_{23}$ & -0 & -0.2 & 0.04 & 0.04 & -0.2 \\
\hline$G_{24}$ & -0.1 & -0 & 0.08 & 0.37 & 0.32 \\
\hline$G_{25}$ & 0.01 & -0.2 & -0.1 & 0 & 0.32 \\
\hline$G_{26}$ & 0.13 & -0.1 & -0.2 & 0.05 & 0.02 \\
\hline$G_{27}$ & 0.02 & -0.1 & -0.2 & 0.1 & 0.23 \\
\hline$G_{28}$ & 0.24 & 0.14 & -0.1 & 0.26 & 0.04 \\
\hline$G_{29}$ & 0.02 & 0.03 & -0.1 & 0.01 & 0.03 \\
\hline$G_{30}$ & 0.08 & -0.1 & 0 & 0 & 0 \\
\hline$G_{31}$ & 0.33 & 0.07 & 0.21 & -0.1 & -0.1 \\
\hline$G_{32}$ & -0.2 & 0.29 & 0.21 & 0.23 & 0.03 \\
\hline$G_{33}$ & -0.1 & 0.03 & 0.18 & -0.1 & -0.1 \\
\hline$G_{34}$ & 0.28 & 0.09 & -0.1 & 0.21 & -0 \\
\hline$G_{35}$ & 0.11 & 0.08 & 0.15 & 0.16 & 0.05 \\
\hline$G_{36}$ & -0.1 & 0.15 & 0.34 & -0.2 & 0 \\
\hline
\end{tabular}

(b) Matrix $\mathbf{B}$

\begin{tabular}{lc}
\hline & $q_{1}$ \\
\hline$S_{1}$ & 0.54 \\
$S_{2}$ & 0.45 \\
$S_{3}$ & 0.46 \\
$S_{4}$ & 0.53 \\
\hline
\end{tabular}

(c) Matrix $\mathbf{C}$

\begin{tabular}{cccc}
\hline & $r_{1}$ & $r_{2}$ & $r_{3}$ \\
\hline$X_{1}$ & 0.45 & -0.2 & 0.21 \\
$X_{2}$ & 0.45 & -0.2 & 0.05 \\
\hline
\end{tabular}


(c) Continued.

\begin{tabular}{lccc}
\hline & $r_{1}$ & $r_{2}$ & $r_{3}$ \\
\hline$X_{3}$ & 0.5 & -0.3 & -0.1 \\
$X_{4}$ & 0.21 & -0 & -0.3 \\
$X_{5}$ & -0.03 & 0.08 & -0.9 \\
$X_{6}$ & -0.21 & -0.3 & 0.06 \\
$X_{7}$ & -0.17 & -0.2 & -0 \\
$X_{8}$ & -0.17 & 0.37 & 0.31 \\
$X_{9}$ & -0.29 & -0.5 & 0.01 \\
$X_{10}$ & -0.28 & -0.5 & 0 \\
\hline
\end{tabular}

(d) Array $\underline{\mathbf{G}}$

\begin{tabular}{ccccccc}
\hline & $q_{1} r_{1}$ & $q_{1} r_{2}$ & $q_{1} r_{3}$ & $q_{2} r_{1}$ & $q_{2} r_{2}$ & $q_{2} r_{3}$ \\
\hline$P_{1}$ & 19.5 & -2.9 & -0.4 & 1.31 & 2.42 & -0.9 \\
$P_{2}$ & 2.25 & 13.2 & -1.5 & -2 & -2.2 & -1.1 \\
$P_{3}$ & 0.15 & -2 & -8.6 & -1.5 & -4.4 & -0.6 \\
$P_{4}$ & 0.62 & -1.2 & 3.53 & -2.6 & -5.2 & -2.4 \\
$P_{5}$ & 0.47 & 0.14 & 0.63 & 0.34 & -2 & 4.83 \\
\hline
\end{tabular}

of the total variability. The components associated with the genotype mode explain, respectively, $27.69 \%, 13.34 \%$, $6.96 \%, 3.77 \%$, and $1.94 \%$, the components of the local mode explain $46.23 \%$ and $7.48 \%$, and the components of the mode attribute explain $27.96 \%, 17.31 \%$, and $8.42 \%$. In this analysis the first component of the local mode is characterized by all the sites with relatively high weights (Matrix B, Table 2).

Figure 3 studies the behavior of the genotypes in relation to the mean environmental for different attributes. Genotypes $10,11,28,31$, and 34 are above mean environmental for the attributes $X_{1}, X_{2}$, and $X_{3}$ in the 4 locations and, in contrast, the genotypes $13,14,15,16,17$, and 32 have a performance below the mean environmental in these attributes. Genotype 4 has good performance in the variables $X_{9}$ and $X_{10}$ to the 4 sites in contrast to genotype 8 which is below the mean environmental in these attributes in the same locations. An opposite behavior occurs in the variable $X_{8}$ in which genotype 4 is below mean environmental and genotypes 8,14 , and 32 have good performance.

The second component of the local mode is characterized by local $S_{2}$ and $S_{4}$ with respective weights of -0.73 and 0.61 (Table 2, Matrix B). This component reflects the contrast between these two locations. In the corresponding joint plot (Figure 4), it can be observed that genotypes 1, 4, 7, 9, 12, and 25 have good behavior with the variable $X_{8}$ for the local $S_{4}$, but are below the mean environmental in local $S_{2}$ for this same attribute. For the same genotypes, the opposite happens, they have good performance in variable $X_{5}$ for the local $S_{2}$, but they are below mean environmental for the same attribute to the local $S_{4}$.

The fundamental difference between AMMI models with multiple attributes and SREG models with multiple attributes is that in the first case study, the two-way interaction considering all the attributes, while in the SREG model, it is possible to study the multivariate behavior of genotypes in relation to the mean environmental.

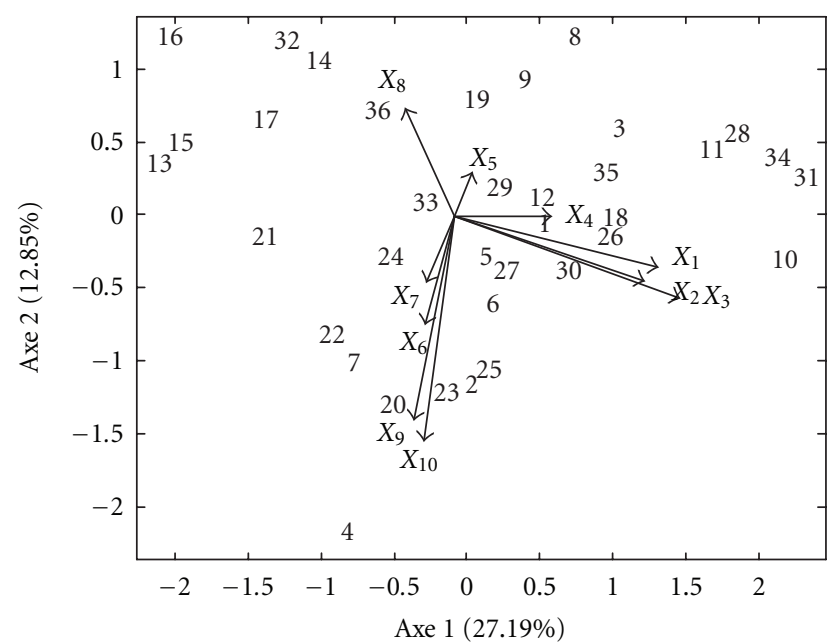

Figure 3: Joint plot conditioned on the first component the location mode for SREG model.

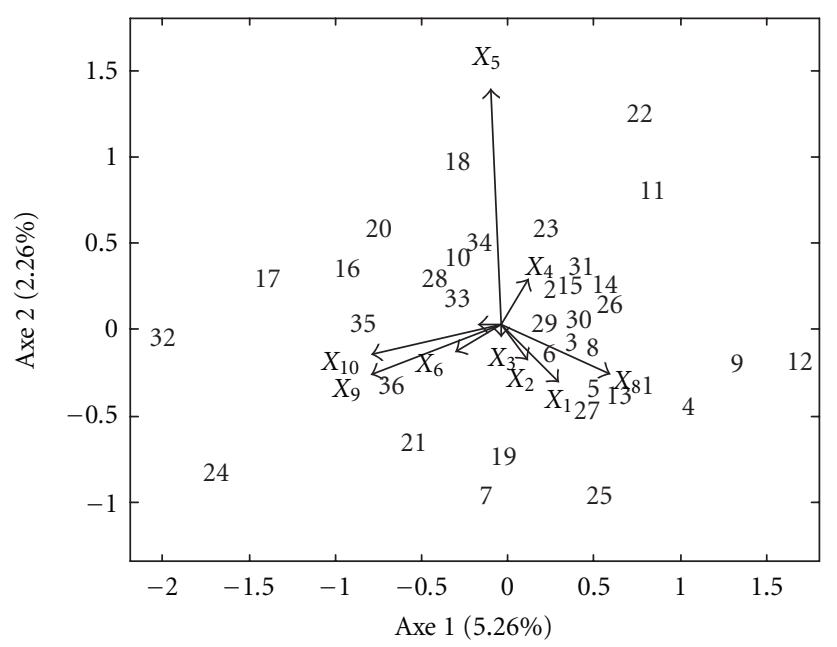

FIGURE 4: Joint plot conditioned on the second component the location mode for SREG model.

\section{Conclusions}

Based on three mode principal components analysis, it is possible to work simultaneously with multiple attributes in the adjustment of AMMI and SREG models, so we can do a multivariate study of the most important aspects of the genotype $\times$ environment interaction and the response of genotypes in different environmental conditions.

When we have many combinations of levels of factors, the conditioned joint plot is a powerful tool to represent three arrays of markers and gives us information on the most important aspects of the response of genotypes. It was possible to detect the combinations of genotypes $x$ locations $\times$ attributes causing the significant interaction and the differential response, that is, identify the best genotypes in view of its adaptability and performance. 


\section{References}

[1] E. J. Williams, "The interpretation of interactions in factorial experiments," Biometrika, vol. 39, pp. 65-81, 1952.

[2] H. F. Gollob, "A statistical model which combines features of factor analytic and analysis of variance techniques," Psychometrika, vol. 33, no. 1, pp. 73-115, 1968.

[3] H. G. Gauch, "Model selection and validation for yield trials with interaction," Biometrics, vol. 44, pp. 705-715, 1988.

[4] J. Crossa and P. L. Cornelius, "Sites regression and shifted multiplicative model clustering of cultivar trial sites under heterogeneity of error variances," Crop Science, vol. 37, no. 2, pp. 405-415, 1997.

[5] J. Crossa, R. C. Yang, and P. L. Cornelius, "Studying crossover genotype $\mathrm{x}$ environment interaction using linear-bilinear models and mixed models," Journal of Agricultural, Biological, and Environmental Statistics, vol. 9, no. 3, pp. 362-380, 2004.

[6] K. R. Gabriel, "Least squares approximation of matrices by additive and multiplicative models," Journal of the Royal Statistical Society: Series B, vol. 40, no. 2, pp. 186-196, 1978.

[7] K. R. Gabriel, "The biplot graphic display of matrices with application to principal component analysis," Biometrika, vol. 58, no. 3, pp. 453-467, 1971.

[8] P. M. Kroonenberg and J. De Leeuw, "Principal component analysis of three-mode data by means of alternating least squares algorithms," Psychometrika, vol. 45, no. 1, pp. 69-97, 1980.

[9] L. R. Tucker, "Some mathematical notes on three-mode factor analysis," Psychometrika, vol. 31, no. 3, pp. 279-311, 1966.

[10] P. M. Kroonenberg and K. E. Basford, "An investigation of multi-attribute genotype response across environments using three-mode principal component analysis," Euphytica, vol. 44, no. 1-2, pp. 109-123, 1989.

[11] K. E. Basford, P. M. Kroonenberg, I. H. Delacy, and P. K. Lawrence, "Multiattribute evaluation of regional cotton variety trials," Theoretical and Applied Genetics, vol. 79, no. 2, pp. 225-234, 1990.

[12] J. Crossa, K. Basford, S. Taba, I. Delacy, and E. Silva, “Threemode analyses of maize using morphological and agronomic attributes measured in multilocational trials," Crop Science, vol. 35, no. 5, pp. 1483-1491, 1995.

[13] M. Varela and V. Torres, "Aplicación del análisis de Componentes Principales de Tres Modos en la caracterización multivariada de somaclones de King Grass," Revista Cubana de Ciencia Agricola, vol. 39, pp. 12-19, 2005.

[14] F. A. Van Eeuwijk and P. M. Kroonenberg, "Multiplicative models for interaction in three-way ANOVA, with applications to plant breeding," Biometrics, vol. 54, no. 4, pp. 13151333, 1998.

[15] M. Varela, J. Crossa, R. J. Adish, K. J. Arun, and R. Trethowan, "Analysis of a three-way interaction including multi-attributes," Australian Journal of Agricultural Research, vol. 57, no. 11, pp. 1185-1193, 2006.

[16] K. E. D’Andrea, M. E. Otegui, and A. J. De La Vega, "Multiattribute responses of maize inbred lines across managed environments," Euphytica, vol. 162, no. 3, pp. 381-394, 2008.

[17] M. Varela, J. Crossa, K. J. Arun, P. L. Cornelius, and Y. Manes, "Generalizing the sites regression model to three-way interaction including multi-attributes," Crop Science, vol. 49, no. 6, pp. 2043-2057, 2009.

[18] M. E. Timmerman and H. A. L. Kiers, "Three-mode principal components analysis: choosing the numbers of components and sensitivity to local optima," British Journal of Mathematical and Statistical Psychology, vol. 53, no. 1, pp. 1-16, 2000. 


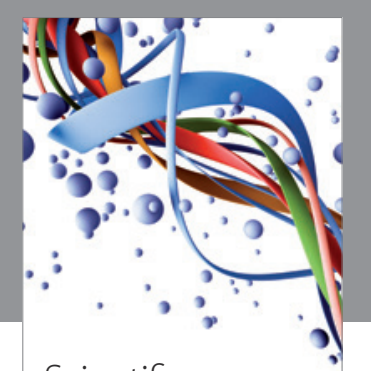

Scientifica
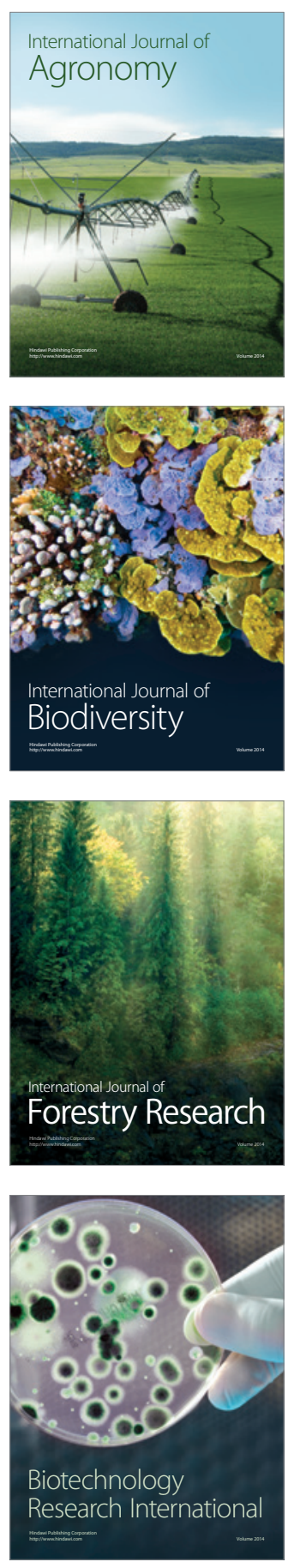
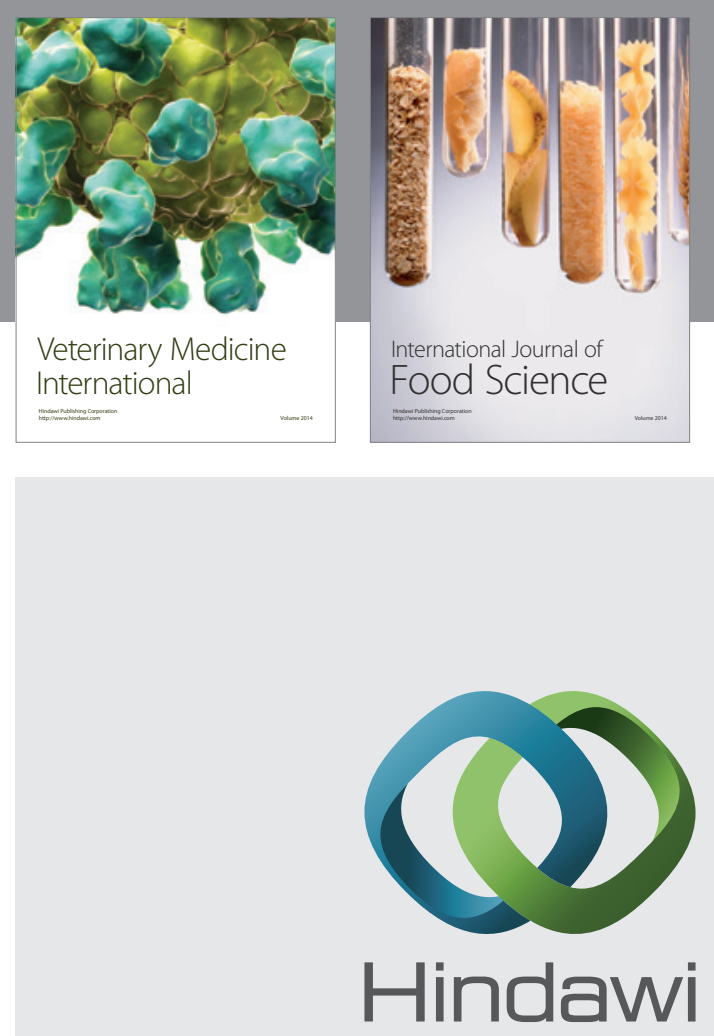

Submit your manuscripts at

http://www.hindawi.com
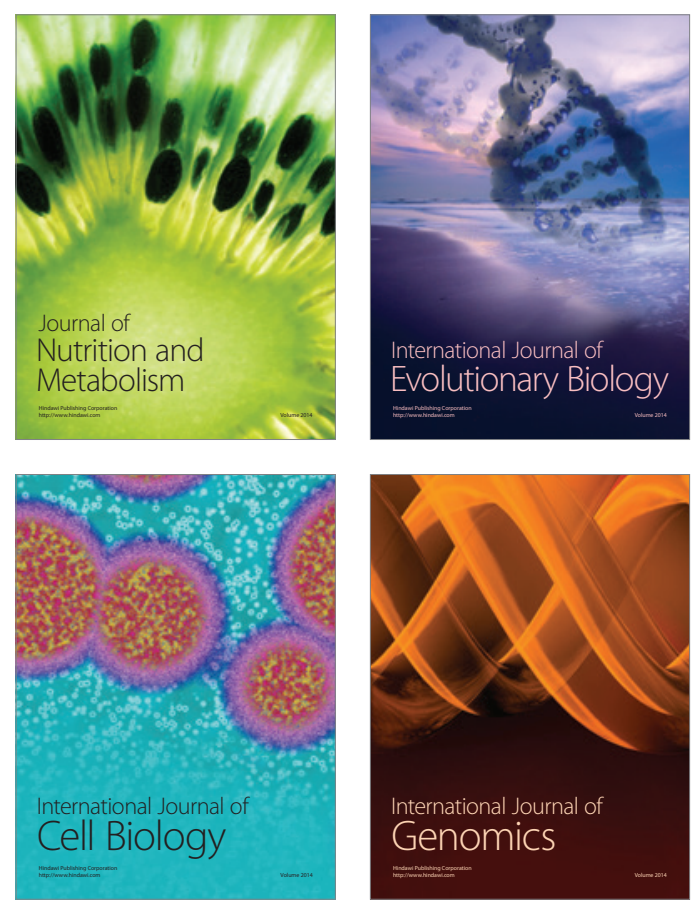
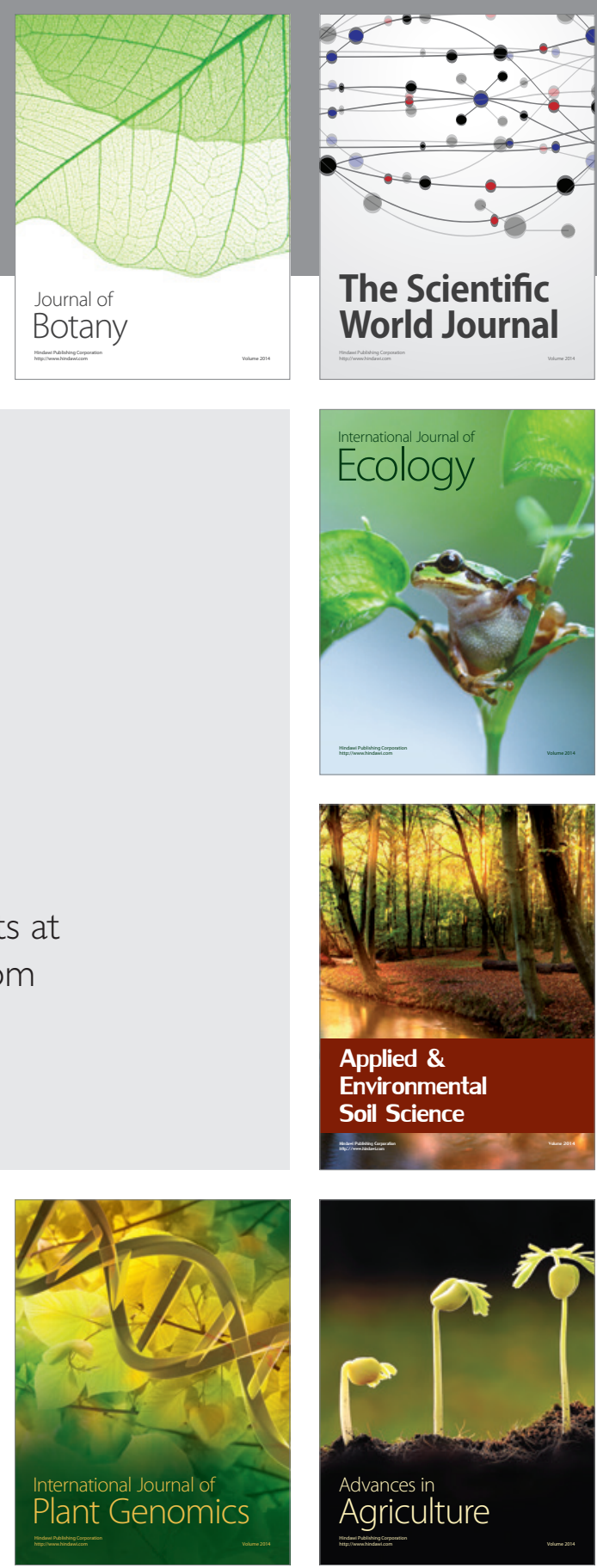

The Scientific World Journal
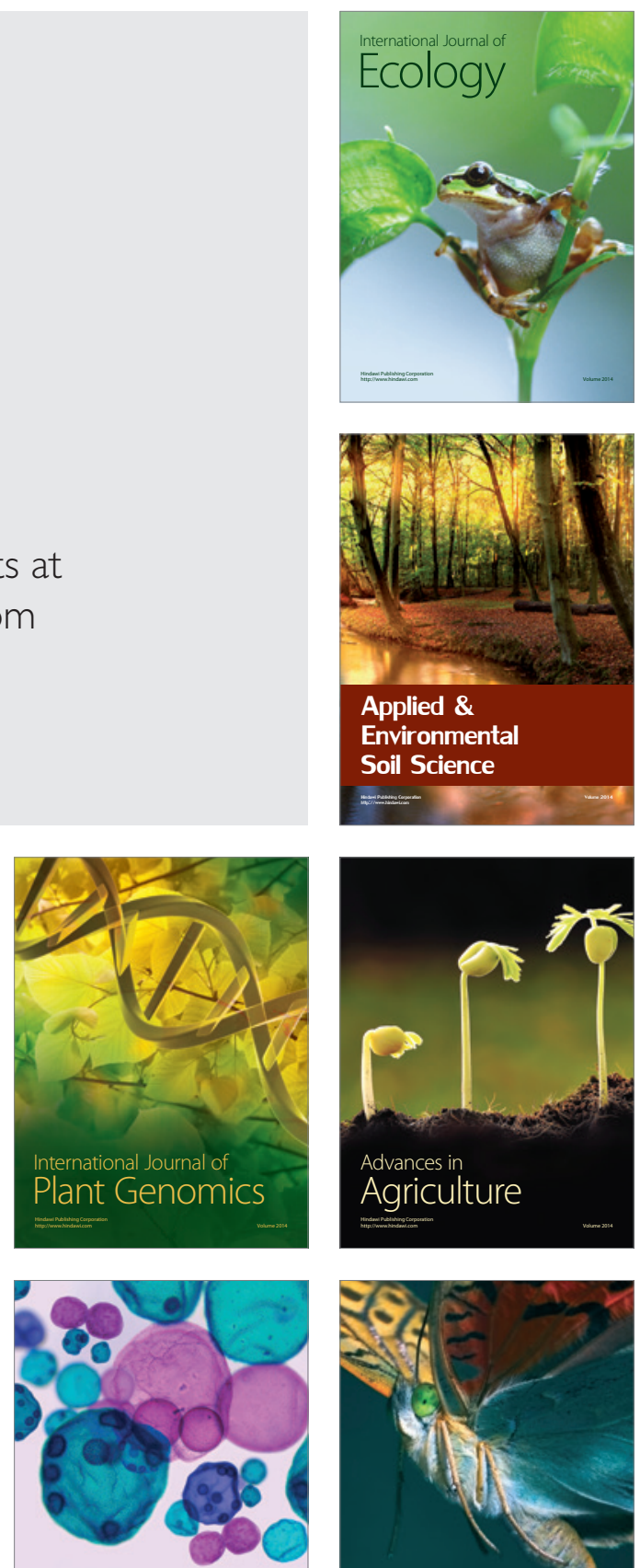

International Journal of Microbiology

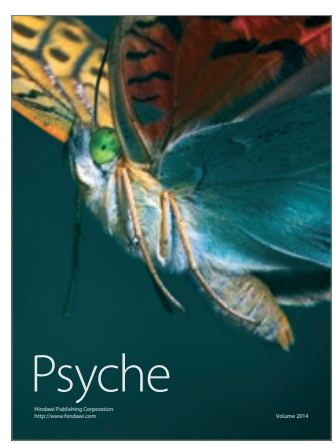

